\title{
Vibrational Spectra of Tetrafluoroethylene and Tetrachloroethylene ${ }^{1,2}$
}

\author{
D. E. Mann, Nicolo Acquista, and Earle K. Plyler
}

\begin{abstract}
The infrared spectra of gaseous tetrafluoroethylene from 22 to $52 \mu$ and liquid tetrachloroethylene from 3 to $52 \mu$ have been determined. Several hitherto unobserved bands were found. New and satisfactory assignments, for which a detailed discussion is given, have been achieved. The out-of-plane force constants are discussed and used to predict the wagging and torsion frequencies of tetrabromoethylene. Tables of the thermodynamic functions for tetrafluoro- and tetrachloroethylene are presented.
\end{abstract}

\section{Introduction}

As part of a more general investigation of the vibrational spectra and force constants of halogenated ethylenes, it was found desirable to reexamine the assignments for tetrafluoroethylene and tetrachloroethylene. $^{3}$ Despite a considerable body of earlier work, several fundamentals in each molecule have remained in doubt or unobserved. The availability of a cesium iodide prism [1] ${ }^{4}$ has made convenient the extension of the observable spectral range to about $52 \mu$, with the result for TFE and TCE that several hitherto unsuspected and otherwise unattainable bands have been revealed. These new data, in conjunction with the recently determined value of the entropy of TFE [2] and some preliminary forceconstant calculations, indicate the need, and provide the basis, for achieving more satisfactory assignments.

Although TCE has been subjected to much more spectroscopic investigation, analysis, and discussion than TFE, its assignment has remained the more questionable. This seems to have been due, at least in part, to the greater inaccessibility of the lowfrequency infrared-active fundamentals of TCE. Its successful analysis may also have been impeded by the lack of adequate data for other molecules closely enough related to TCE to render some correlations useful. Tetrafluoroethylene bears a sufficiently close resemblance, both spectrally and structurally, to its chlorine analogue to make it profitable to consider them together. Moreover, the entropy data lend additional credibility to the present TFE assignment, so that its use as a guide may be at least partially justified.

\section{Experimental Methods}

The general method of measurement has been described previously $[3,4]$. To ensure adequate resolution over the range 3 to about $52 \mu$, prisms of $\mathrm{NaCl}$, $\mathrm{KBr}$, and CsI were employed in appropriate regions. The first two were used in Perkin-Elmer model 21 and Baird Associates instruments, respectively, and the

Presented before the American Physical Society at its meeting in Washington, D. C., on May 1, 1953 .

2 This work has been supported in part by the ONR under contract NAonr $112-51$.

Hereafter in this paper tetrafluorethylene, $\mathrm{F}_{2} \mathrm{C}: \mathrm{CF}_{2}$, will be abbreviated to TFE, and tetrachloroethylene, $\mathrm{Cl}_{2} \mathrm{C}: \mathrm{CCl}_{2}$, will be contracted to TCE.

4 Figures in brackets indicate the literature references at the end of this paper. cesium iodide prism was used with a Perkin-Elmer model $12 \mathrm{C}$ spectrometer.

A pure sample of gaseous TFE was examined only in the region 22 to $52 \mu$ because the earlier investigation by Nielsen, Claassen, and Smith [5] of its infrared spectrum between 2 and $22 \mu$ is satisfactory. Recent studies of the infrared spectrum of TCE have been made by Plyler [6], who reported four bands in the region 23 to about $40 \mu$, and by Bernstein [7], who investigated the region between 2.5 and $25 \mid \mu$. It was thought desirable to reexamine the previously studied range, using a highly purified sample of TCE, as well as to extend it to $52 \mu$. There are some discrepancies between the spectrum presented here and that displayed in [7]. These may be largely due to differences in purity and resolution. The sample of TCE used in this work had been specially purified by distillation through a 40 -plate Piros-Glover spinning band still, and by passage through a 10-in. column of silica gel.

The spectral curves for TFE and TCE are displayed in figures 1 and 2 , respectively. A complete tabulation of the observed data for the chloro compound, together with its assignment, is given in table 1.

\section{Discussion}

\subsection{Spectra of Tetrafluoroethylene}

The infrared spectrum of gaseous TFE has been examined by Torkington and Thompson [8], and more thoroughly by Nielsen, Claassen, and Smith [5] from 2 to $22 \mu$. The region between 22 and $37 \mu$ was covered by Plyler with the aid of a KRS-5 prism [5]. Raman spectra of gaseous TFE, including depolarization factors, were also obtained by Nielsen, Claassen, and Smith. Monfils and Duchesne [9] have reported Raman spectra for the liquid but did not give polarization data.

The infrared band at $406 \mathrm{~cm}^{-1}$ observed by Plyler, was reported in [5] to have a type $\mathrm{C}$ contour. From figure 1 it is evident that this observation is confirmed despite the appearance of an overlapped band in the $R$ branch. Apart from the very weak peak adjacent to the $P$ branch of the $406 \mathrm{~cm}^{-1}$ band, the intermediate region is quite barren until the strong absorption around $218 \mathrm{~cm}^{-1}$ is reached. The resolu- 
TABLE 1. Infrared and Raman spectra of $\mathrm{Cl}_{2} \mathrm{C}: \mathrm{CCl}_{2}$ (liquid)

\begin{tabular}{|c|c|c|c|c|}
\hline \multicolumn{2}{|c|}{ Raman } & \multicolumn{2}{|c|}{ Infrared a } & \multirow{2}{*}{ Interpretation } \\
\hline$\nu$ & $(\mathrm{I}, \rho)$ & $\nu$ & $I$ & \\
\hline $\mathrm{cm}^{-1}$ & & $\mathrm{~cm}^{-1}$ & & \\
\hline 218 & $(00,-)$ & 224 & w & $\begin{array}{l}2 \times 110=220\left(A_{g}\right) \\
\nu_{7}\left(b_{1 u} ; \beta-\mathrm{CCl}_{2}\right)\end{array}$ \\
\hline 235 & $(10,0.62)$ & - - - nee & $-\cdots--$ & $\nu_{3}\left(a_{g} ; \delta-\mathrm{CCl}_{2}\right)$ \\
\hline & & 288 & W & $\nu_{12}\left(b_{3 u} ; \delta-\mathrm{CCl}_{2}\right)$ \\
\hline & & 310 & vw & $288+\nu_{i}-\nu_{i}$ \\
\hline & & 328 & $\mathrm{vw}$ & $777-447=330\left(B_{3 u}\right)$ \\
\hline & & 345 & vw & $\left(\nu_{6}\right)^{\mathrm{b}}$ \\
\hline \multirow[t]{3}{*}{ b 347} & $(4,0.83)$ & $\ldots \ldots$ & $\ldots \ldots$ & $\nu_{6}\left(b_{1 g} ; \rho-\mathrm{CCl}_{2}\right)$ \\
\hline & & 405 & vw & $176+235=411\left(B_{2 u}\right)$ \\
\hline & & 433 & v̀w & $777-347=430\left(B_{2 u}\right)$ \\
\hline 447 & $(15,0.14)$ & - - - - - & - . - . - & $\nu_{2}\left(a_{g} ; \nu-\mathrm{CCl}\right)$ \\
\hline \multirow[t]{2}{*}{464} & $(1 / 2,-)$ & ----- & $--\cdots$ & $2 \times 235=470\left(A_{g}\right)$ \\
\hline & & 465 & vw & $224+235=459\left(B_{1 u}\right) ; 908-447=461\left(B_{2 u}\right)$ \\
\hline \multirow[t]{4}{*}{512} & $(4,0.77)$ & 513 & VW & $\begin{array}{l}\nu_{8}\left(b_{2 g} ; \beta-\mathrm{CCl}_{2}\right) \\
176+347=523\left(B_{3 u}\right)\end{array}$ \\
\hline & & 526 & vw & $235+288=523\left(B_{3 u}\right)$ \\
\hline & & 540 & vw & $777-235=542\left(B_{3 u}\right)$ \\
\hline & & 559 & vw & $908-347=561\left(B_{3 u}\right)$ \\
\hline \multirow[t]{2}{*}{574} & $(0,-)$ & ...... & - . - . - & $2 \times 288=576\left(A_{g}\right)$ \\
\hline & & 620 & vw & $176+447=623\left(B_{2 u}\right)$ \\
\hline \multirow[t]{3}{*}{631} & $(00,-)$ & -.... - & $\ldots \ldots$ & $908-288=620\left(B_{1 g}\right)$ \\
\hline & & 641 & vw & $288+347=635\left(B_{2 u}\right)$ \\
\hline & & 679 & w & $224+447=671\left(B_{1 u}\right)$ \\
\hline \multirow[t]{3}{*}{726} & $(00,-)$ & - . - . - & - . . . - & $2 \times 347=694\left(A_{g}\right) ; 235+512=747\left(B_{2 g}\right)$ \\
\hline & & 755 & s & $224+512=736\left(B_{3 u}\right) ; 288+447=735\left(B_{3 u}\right)$ \\
\hline & & 777 & vs & $\nu_{11}\left(b_{3 u} ; \nu-\mathrm{CCl}\right)$ \\
\hline \multirow[t]{5}{*}{784} & $(00,-)$ & - n- - - & $-\ldots-\ldots$ & $347+447=794\left(B_{1 g}\right)$ \\
\hline & & 800 & s & $288+512=800\left(B_{1 u}\right)$ \\
\hline & & 908 & vvs & $\nu_{9}\left(b_{2 u} ; \nu-\mathrm{CCl}\right)$ \\
\hline & & 979 & $\mathrm{~m}$ & $224+235+512=971\left(B_{3 u}\right)$ \\
\hline & & 994 & $\mathrm{~m}$ & $235+777=1012\left(B_{3 u}\right)$ \\
\hline 1000 & $(00,-)$ & - n...- & - - - - - & $\nu_{5}\left(b_{1 g} ; \nu-\mathrm{CCl}\right)$ \\
\hline \multirow[t]{10}{*}{1025} & $(1, \mathrm{p})$ & - - - - & - - - - - & $2 \times 512=1024\left(A_{g}\right)$ \\
\hline & & 1102 & $\mathrm{~m}$ & $224+347+512=1083\left(B_{2 u}\right)$ \\
\hline & & 1121 & $\mathrm{~m}$ & $347+777=1124\left(B_{2 u}\right)$ \\
\hline & & 1142 & $\mathrm{~m}$ & $235+908=1143\left(B_{2 u}\right)$ \\
\hline & & 1171 & $\mathrm{w}$ & $176+1000=1176\left(B_{3 u}\right)$ \\
\hline & & 1200 & $\mathrm{w}$ & $224+447+512=1183\left(B_{3 u}\right)$ \\
\hline & & 1222 & w & $447+777=1224\left(B_{3 u}\right)$ \\
\hline & & 1253 & $\mathrm{w}$ & $347+908=1255\left(B_{3 u}\right)$ \\
\hline & & 1355 & $\mathrm{~m}$ & $447+908=1355\left(\mathrm{~B}_{2 u}\right)$ \\
\hline & & 1392 & vw & $176+235+1000=1411\left(B_{3 u}\right)$ \\
\hline \multirow[t]{2}{*}{1441} & $(0 ?,-)$ & - - - - & - - - - - & $447+1000=1447\left(B_{1 g}\right)$ \\
\hline & & 1481 & vw & $2 \times 288+908=1484\left(B_{2 u}\right)$ \\
\hline \multirow[t]{6}{*}{1571} & $(10,0.36)$ & - . - - - & - . - - - & $\nu_{1}\left(a_{g} ; \nu-\mathrm{CC}\right)$ \\
\hline & & 1577 & w & $347+447+777=1571\left(B_{2 u}\right)$ \\
\hline & & 1733 & vw & $288+447+1000=1735\left(B_{2 u}\right)$ \\
\hline & & 1751 & $\mathrm{w}$ & $176+1571=1747\left(B_{2 u}\right)$ \\
\hline & & 1773 & $\mathrm{w}$ & $777+1000=1777\left(B_{2 u}\right)$ \\
\hline & & 1795 & vw & $224+1571=1795\left(B_{1 u}\right)$ \\
\hline \multirow[t]{3}{*}{1819} & $(0,-)$ & -..-- & - . - - & $2 \times 908=1816\left(A_{g}\right)$ \\
\hline & & 1862 & w & $288+1571=1859\left(B_{3 u}\right)$ \\
\hline & & 1887 & $\mathrm{w}$ & $908+1000=1908\left(B_{3 u}\right)$ \\
\hline \multirow[t]{6}{*}{1998} & $(1 / 2,-)$ & - - - - - & - - - - - & $2 \times 1000=2000\left(A_{g}\right)$ \\
\hline & & 2475 & W & $908+1571=2479\left(B_{2 u}\right)$ \\
\hline & & 2717 & vw & $235+908+1571=2714\left(B_{2 u}\right)$ \\
\hline & & 2755 & vw & $777+2 \times 1000=2777\left(B_{3 u}\right)$ \\
\hline & & 2890 & vw & $908+2 \times 1000=2908\left(B_{2 u}\right)$ \\
\hline & & 3448 & vw & $908+1000+1571=3479\left(B_{3 u}\right)$ \\
\hline
\end{tabular}




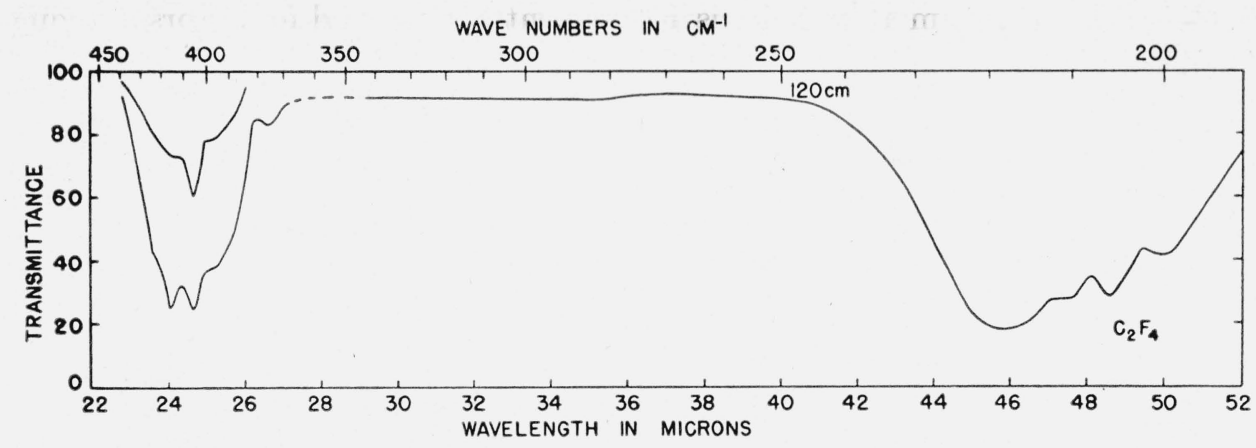

FiguRE 1. Infrared spectrum of gaseous $\mathrm{F}_{2} \mathrm{C}: \mathrm{CF}_{2}$ from 22 to $52 \mu$.
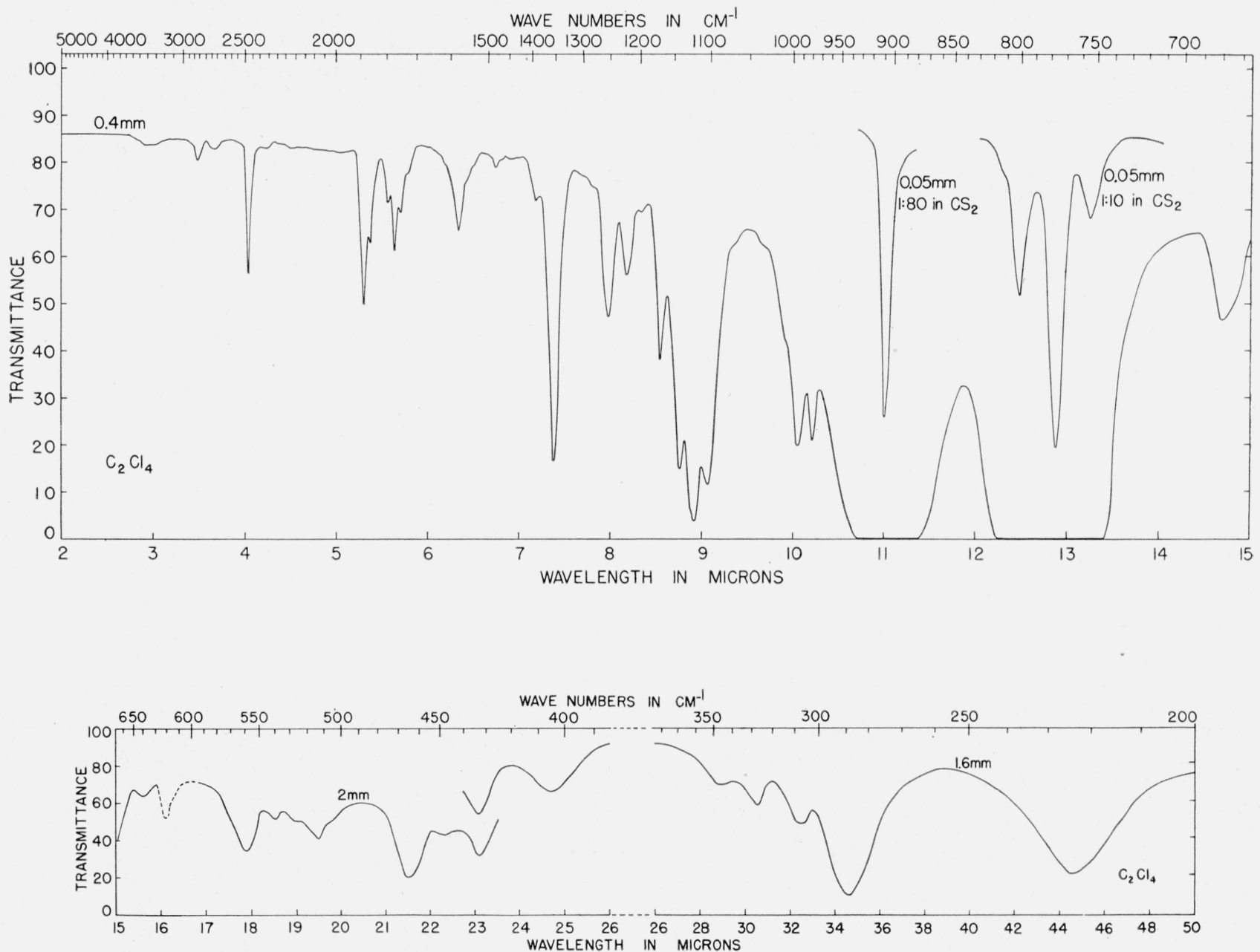

Figure 2. Infrared spectrum of liquid $\mathrm{Cl}_{2} \mathrm{C}: \mathrm{CCl}_{2}$ from 2 to $52 \mu$.

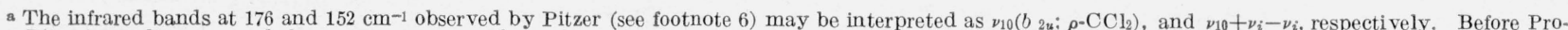

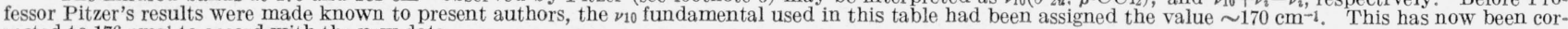
rected to $176 \mathrm{~cm}^{-1}$ to accord with the new data.

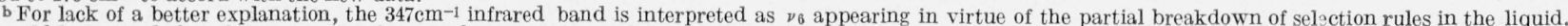

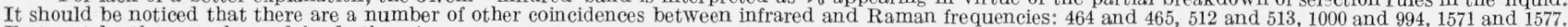
Fortunately, these can be explained otherwise. 
tion of the cesium iodide prism is not sufficient to reveal much structure in this region, and the bumps on the low-frequency shoulder should be regarded with some scepticism. Though they appear to be real, they may derive at least in part from some uncertainty in the background-absorption correction.

The band at $218 \mathrm{~cm}^{-1}$ undoubtedly represents the hitherto unobserved $b_{2 u}$ rocking fundamental. It had been placed at $245 \mathrm{~cm}^{-1}$ by Nielsen, Claassen, and Smith on the basis of their interpretation of several combination bands. A value of $250 \mathrm{~cm}^{-1}$ was deduced by Monfils and Duchesne [9] from a force-constant analysis. Inasmuch as 406 and 558 $\mathrm{cm}^{-1}$ have been unambiguously established as representing the $b_{1 u}$ wagging and $b_{3 u}$ deformation fundamentals, respectively, only the inactive torsion and the Raman-active vibrations need be considered in order to complete the assignment.

The polarization measurements of Nielsen, Claassen, and Smith leave no doubt as to the correctness of their assignment of 394,778 , and $1872 \mathrm{~cm}^{-1}$ to the totally symmetric $\left(a_{g}\right)$ vibrations. Moreover, their interpretation of the $503-517 \mathrm{~cm}^{-1}$ doublet as the $b_{2 g}$ fundamental, and their deduction of a frequency around $550 \mathrm{~cm}^{-1}$ for the lower of the $b_{1 g}$ vibrations is supported by the work of Monfils and Duchesne [9] on the Raman spectrum of liquid TFE. Although the latter workers originally questioned [9] the assignment by Nielsen, Claassen, and Smith of a very feeble line at about $1340 \mathrm{~cm}^{-1}$ to $b_{1 g}$, they appear now [10] to have accepted this interpretation. The present analysis also favors $1340 \mathrm{~cm}^{-1}$ for the higher $b_{1 \mathrm{~g}}$ vibration. Only the inactive torsion frequency remains unassigned.

\subsection{Torsion Frequency of Tetrafluoroethylene}

In crder to obtain a rough estimate of the torsion frequency, the assumption was made that the force constant for the twisting motion in TFE is the same as that obtained by Arnett and Crawford [11] for ethylene, $\mathrm{H}_{2} \mathrm{C}: \mathrm{CH}_{2}{ }^{5}$. In units of $10^{-11} \mathrm{erg} / \mathrm{radian}^{2}$ the constant obtained by Arnett and Crawford is $F_{\tau}=0.269$. With the distances and angles appropriate to TFE [13], this leads to a value of $199 \mathrm{~cm}^{-1}$ for the torsion frequency. Hence, the interesting possibility exists that one of the peaks around $205 \mathrm{~cm}^{-1}$ in the infrared spectrum of TFE may arise from the torsion vibration made active by Coriolis interaction with the neighboring $b_{2 u}$ fundamental at $218 \mathrm{~cm}^{-1}$. Attempts to determine the torsion frequency directly from the observed combination bands tend to support a value in the range 190 to $200 \mathrm{~cm}^{-1}$. Fortunately, the entropy of TFE has been determined very recently [2] and provides valuable evidence in favor of the complete assignment, while placing the torsion frequency at $190 \mathrm{~cm}^{-1}$. Small inaccuracies in the fundamental frequencies, together with the experimental uncertainties in the entropy value, may account for the slight discrepancy. Because of the lack of stronger evidence favoring the higher value, $190 \mathrm{~cm}^{-1}$ was

5 For brief mention of this point, see the paper by Torkington on TCE [12] adopted for the torsion frequency. The corresponding force constant then becomes $F_{\tau}=0.245$. The final and complete assignment is given in table 3 .

\subsection{Spectra of Tetrachloroethylene}

The infrared spectrum of liquid TCE was first studied by Coblentz [14]. Bonino examined a small portion of its spectrum in 1925 [15], and Spence and Easley observed the region between 0.8 and $3 \mu$ but found no bands [16]. Another early study of its near infrared spectrum was made by Freymann [17]. In $1934 \mathrm{Wu}$ reported four bands, $755(\mathrm{~m})$, 782(s), 802(s), 913(s), for gaseous TCE [18]. A few years later Duchesne and Parodi reported infrared bands at 332 and $387 \mathrm{~cm}^{-1}$ [19]. Bernstein has observed the spectrum of TCE from 2.5 to $25 \mu$ [7], and Plyler has extended the range to about $40 \mu[6]$. In the present work the entire region 3 to $52 \mu$ has been investigated. ${ }^{6}$

The Raman spectrum of liquid TCE has been extensively investigated [20 to 31$]$. With the exception of the recent work of Sanyal [31], the available data have been considerably augmented and carefully reviewed by Wittek [29]. Summaries have also been given by Kohlrausch [32], Wu [33], and Herzberg [34]. The frequencies, relative intensities, and depolarization factors ${ }^{7}$ given by Wittek are: $218(00,-), 235(10,0.62), 347(4,0.83), 447(15,0.14)$, $464(1 / 2,-), 512(4,0.77), 574(0,-), 631(00,-), 726(00,-)$, $784(00,-), 1000(00,-), 1025(1, p), 1441(0 ?,-), 1571-$ $(10,0.36), 1819(0,-), 1998(1 / 2,-)$. Sanyal [31] reported for liquid TCE $238(7, \mathrm{dp}), 346(4, \mathrm{dp}), 382(\mathrm{Ob},-), 450$ $(9, \mathrm{p}), 516(3, \mathrm{dp}), 1572(10, \mathrm{dp})$; and for the solid at $-150^{\circ} \mathrm{C}$, he found $242(2,-), 346(1,-), 380(0,-)$, $454(1,-), 1576(58,-)$. The line at $382 \mathrm{~cm}^{-1}$ found by Sanyal was also reported by $\mathrm{Wu}[27]$ but was shown by Wittek to be spurious. Moreover, the depolarized character ascribed by Sanyal to the $1572 \mathrm{~cm}^{-1}$ line is in disagreement with all prior polarization measurements [25 to 27,29$]$. Wittek's results are used in this paper.

The infrared spectrum of liquid TCE is shown in figure 2. The wave numbers and relative intensities of the observed bands, together with Wittek's Raman data and the present interpretation, are given in table 1.

\subsection{Interpretation of the Vibrational Spectra Tetrachloroethylene}

The Raman data for TCE clearly prescribe the three $a_{1 g}$ fundamentals: 235, 447, and $1571 \mathrm{~cm}^{-1}$. These correspond approximately to the totally symmetric $\mathrm{CCl}_{2}$ deformation $\left(\delta-\mathrm{CCl}_{2}\right), \mathrm{CCl}$ stretching $(\nu-\mathrm{CCl})$, and $\mathrm{CC}$ stretching $(\nu-\mathrm{CC})$, respectively. ${ }^{8}$

${ }^{6}$ After the work described in this paper was completed a private communication was received from K. S. Pitzer stating that the infrared spectrum of TCF had been observed in his laboratory down to about $135 \mathrm{~cm}^{-1}$. Outside of the range used in the present investigation, two bands, a strong one at $176 \mathrm{~cm}^{-1}$ and a somewhat weaker one at $152 \mathrm{~cm}^{-1}$, were observed.

7 The depolarization factors are averages of the results given by Wittek for four separate determinations. For the $1025 \mathrm{~cm}^{-1}$ line, the data are too few to justify averaging but suffice to indicate its character.

8 See [4] for a description of the notation used here to represent the various modes. 
There remain three Raman-active fundamentals: a $\mathrm{CCl}$ stretching and $\mathrm{CCl}_{2}$ rocking $\left(\rho-\mathrm{CCl}_{2}\right)$ in $b_{1 g}$, and the out-of-plane $\mathrm{CCl}_{2}$ wagging $\left(\beta-\mathrm{CCl}_{2}\right)$ in $b_{2 g}$. Apart from the lines already assigned to $a_{1 g}$ vibrations, only 347 and 512 have appreciable intensity. As they are depolarized they cannot be overtones, nor, indeed, is it reasonable to suppose they arise from sum bands. In fact, the weak polarized line at $1025 \mathrm{~cm}^{-1}$ is most readily interpreted as $2 \times 512$. As fundamentals, they must be assigned in some manner to the $b_{1 g}$ and $b_{2 g}$ species. Analogy with TFE suggests that the $b_{1 g}$ stretching frequency in TCE is high, on a par with the infrared-active stretchings at 777 and $908 \mathrm{~cm}^{-1}$, and that it would appear only feebly in the Raman spectrum. Hence, 347 and 512 may be assigned to the $b_{1 g}$ rocking and $b_{2 g}$ wagging modes, though it is not yet clear in what order. For the $b_{1 g}$ stretching one of the very weak lines at 726,784 , or $1000 \mathrm{~cm}^{-1}$ may be chosen. The repeated occurrence of the latter in combinations and its usefulness in explaining the line at 1998 as $2 \times 1000$ lends considerable support to its interpretation as a fundamental.

It is now convenient to consider the infraredactive vibrations. The very strong bands at 777 and $908 \mathrm{~cm}^{-1}$ may at once be assigned to the $\mathrm{CCl}$ stretchings in $b_{2 u}$ and $b_{3 u}$, but in the absence of characteristic envelopes, it is not possible to determine uniquely their correspondence with the species. The infrared spectrum of TFE suggests that the $b_{1 u}$ wagging and the remaining $b_{2 u}$ and $b_{s u}$ modes of TCE give rise to moderately strong bands. Figure 2 shows that between the intense cluster around $777 \mathrm{~cm}^{-1}$ and the lower limit of the present range of observation, $190 \mathrm{~cm}^{-1}$, there appear only two relatively strong bands, viz., those at 288 and $224 \mathrm{~cm}^{-1}$. It will be recalled that the $b_{3 u}, b_{1 u}$, and $b_{2 u}$ angular modes in TFE occur at 558, 406, and $218 \mathrm{~cm}^{-1}$. This suggests that the TCE rocking frequency occurs well below the $224 \mathrm{~cm}^{-1}$ band. At the same time, however, this analogy with TFE requires the assignment of $288 \mathrm{~cm}^{-1}$ to the $b_{3 u}$ deformation and 224 $\mathrm{cm}^{-1}$ to the $b_{1 u}$ wagging motion. The attempt to infer the frequency of the $b_{1 u}$ rocking from the observed combination bands leads to a value around $170 \mathrm{~cm}^{-1} \cdot 9$

Although it seems clear that aside from the torsion vibration all the fundamental frequencies are now known, it is still necessary to determine unequivocally the species to which the pairs 347,512 and 777,908 belong. An analysis of the force constants for the $b_{1 g}$ block leads to the conclusion that the frequency $512 \mathrm{~cm}^{-1}$ is far too high to be ascribed to the rocking mode. It must, therefore, correspond to the $b_{2 g}$ wagging, whereas 347 may be satisfactorily interpreted as the $b_{1 g}$ rocking frequency. Contrary to the objections raised by Torkington [12], this assignment leads to reasonable force constants for the out-of-plane bending modes. In table 2 are

\footnotetext{
9 The results quoted in footnote 6 provide encouraging support for this pre
} diction. given the principal and interaction constants for the wagging motions in ethylene, TFE, and TCE. As was to be expected both $H$ and $h$ are much larger for TFE than for ethylene. For TCE, on the other hand, the principal constant $H$ shows a marked decrease from its value for TFE, approaching, in fact, that for ethylene. Most interesting, however, is the zero interaction constant for TCE. Indeed, it may be anticipated that $h$ also vanishes for the next higher member of the series, viz., tetrabromoethylene (TBE). Moreover, it is reasonable to expect that for TBE the constant $H$ will be close to its value for TCE, being perhaps slightly smaller. If, then, the TCE constants are transferred to TBE, the $b_{1 u}$ and $b_{2 g}$ frequencies for the latter are found to be 200 and $489 \mathrm{~cm}^{-1}$, respectively. The Raman data given for TBE by Kohlrausch [32] include a weak line at $463 \mathrm{~cm}^{-1}$, which he has assigned to the $b_{2 g}$ wagging mode. If this interpretation of the $463 \mathrm{~cm}^{-1}$ is correct and $h$ is taken to be zero, then $H$ becomes 0.238 , which is to be compared with 0.266 for TCE. It is, moreover, now possible to predict the value of the $b_{1 u}$ wagging frequency in TBE. With $H=0.238$, $h=0$, this vibration is calculated to occur at $189 \mathrm{~cm}^{-1}$.

TABLE 2. Frequencies and force constants for wagging modes of $\mathrm{H}_{2} \mathrm{C}: \mathrm{CH}_{2}, \mathrm{~F}_{2} \mathrm{C}: \mathrm{CF}_{2}$, and $\mathrm{Cl}_{2} \mathrm{C}: \mathrm{CCl}_{2}$

\begin{tabular}{|c|c|c|c|}
\hline Constants & $\mathrm{H}_{2} \mathrm{C}: \mathrm{CH}_{2}^{\mathrm{a}}$ & $\mathrm{F}_{2} \mathrm{C}: \mathrm{CF}_{2}$ & $\mathrm{Cl}_{2} \mathrm{C}: \mathrm{CCl}_{2}$ \\
\hline $\begin{array}{l}\nu 7\left(b_{1 u}\right) \\
\nu_{8}\left(b_{2 g}\right) \\
b H \\
b h\end{array}$ & $\begin{array}{l}949.2 \\
943 \\
0.230 \\
.033\end{array}$ & $\begin{array}{l}406 \\
508 \\
\quad 0.326 \\
\quad .127\end{array}$ & $\begin{array}{r}224 \\
512 \\
0.266 \\
\quad .000\end{array}$ \\
\hline
\end{tabular}

a The data for ethylene are taken from the paper by Arnett and Crawford [11].

b The principal constant $H$ and the interaction constant $h$ are given here in units of $10^{-11} \mathrm{erg} / \mathrm{radian}^{2}$. The actual symmetrized constant for the $b_{1 u}$ motion is $(H+h)$, and that for $b_{2 g}$ is $(H-h)$.

The correlation of the 777 and $908 \mathrm{~cm}^{-1}$ bands with the species $b_{2 u}$ and $b_{3 u}$ is hindered by the absence of the usual aids to assignment. Analogy with TFE suggests that $908 \mathrm{~cm}^{-1}$ refers to the $b_{2 u}$ stretching mode and $777 \mathrm{~cm}^{-1}$ to that in $b_{3 u}$. Because the remainder of the assignment is fairly well established, a ferce-constant calculation is justified. As yet unpublished results obtained by D. E. Mann for TCE, with the aid of a Urey-Bradley type of potential function [35], indicate that the suggested analogy with the TFE assignment is probably correct. ${ }^{10}$

All that is needed now to complete the assignment is a value for the torsion frequency. If we use for TCE the torsion constant previously determined for TFE, the frequency is calculated to be $106 \mathrm{~cm}^{-1}$. This provides a plausible explanation for the very weak Raman line at $218 \mathrm{~cm}^{-1}$ as the overtone of the torsion fundamental. To avoid imputing too much significance to this calculation, the value of the frequency has been rounded to $110 \mathrm{~cm}^{-1}$. The final assignment is given in table 3 .

${ }^{10} \mathrm{It}$ is worth pointing out, however, that some modification of the simple Urey-Bradley field [35] is needed. In particular, the addition of a constant that describes the effect of the interaction of the $\mathrm{CCl}_{2}$ groups in the rocking modes seems desirable. 
TABLE 3. Fundamental vibration frequencies for $\mathrm{F}_{2} \mathrm{C}: \mathrm{CF}_{2}$ and $\mathrm{Cl}_{2} \mathrm{C}: \mathrm{CCl}_{2}$

\begin{tabular}{|c|c|c|c|c|}
\hline $\begin{array}{l}\text { Species } \\
\left(\mathrm{V}_{\mathrm{h}}\right)\end{array}$ & Number & $\begin{array}{l}\text { Designa- } \\
\text { tion }\end{array}$ & $\mathrm{F}_{2} \mathrm{C}: \mathrm{CF}_{2}$ & $\mathrm{Cl}_{2} \mathrm{C}: \mathrm{CCl}_{2}$ \\
\hline $\begin{array}{l}a_{g} \ldots \ldots \\
a_{\mathrm{w}} \\
b_{1 \mathrm{~g}} \\
b_{1 \mathrm{w}} \\
b_{2 \mathrm{~g}} \\
b_{2 \mathrm{w}} \\
b_{3 \mu}\end{array}$ & 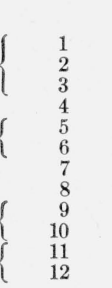 & $\begin{array}{c}\nu-\mathrm{CC} \\
\nu-\mathrm{CX} \\
\delta-\mathrm{CX}_{2} \\
\tau \\
\nu-\mathrm{CX} \\
\rho-\mathrm{CX}_{2} \\
\beta-\mathrm{CX}_{2} \\
\beta-\mathrm{CX}_{2} \\
\nu-\mathrm{CX}_{2} \\
\rho-\mathrm{CX}_{2} \\
\nu-\mathrm{CX}_{2} \\
\delta-\mathrm{CX}_{2}\end{array}$ & $\begin{array}{r}c m^{-1} \\
1872 \\
778 \\
394 \\
190 \\
1340 \\
551 \\
406 \\
508 \\
1337 \\
218 \\
1186 \\
558\end{array}$ & $\begin{array}{c}c m^{-1} \\
1571 \\
447 \\
235 \\
110 \\
1000 \\
347 \\
224 \\
512 \\
908 \\
2176 \\
777 \\
288\end{array}$ \\
\hline
\end{tabular}

a See footnote 6 .

\section{Thermodynamic Functions}

The thermodynamic functions to the rigid-rotator, harmonic-escillator approximation were computed for TFE and TCE in their ideal gaseous state. The molecular constants used were taken from [13] and [36], but the assignments were those given in table 3 . The results given in tables 4 and 5 are taken from the more complete tables calculated with the aid of SEAC.

TABLE 4. Calculated thermodynamic functions in dimensionless units for $\mathrm{F}_{2} \mathrm{C}: \mathrm{CF}_{2}$ as an ideal gas

\begin{tabular}{|c|c|c|c|c|}
\hline$T$ & $C_{p}^{\circ} / R$ & $\left(H^{\circ}-E_{0}^{\circ}\right) / R T$ & $-\left(F^{\circ}-E_{0}^{\circ}\right) / R T$ & $S^{\circ} / R$ \\
\hline $\begin{array}{l}{ }^{\circ} K \\
197.53 \\
300 \\
400 \\
500 \\
600\end{array}$ & $\begin{array}{r}7.787 \\
9.707 \\
11.054 \\
12.073 \\
12.849\end{array}$ & $\begin{array}{l}5.467 \\
6.607 \\
7.559 \\
8.364 \\
9.050\end{array}$ & $\begin{array}{l}27.013 \\
29.526 \\
31.561 \\
33.336 \\
34.924\end{array}$ & $\begin{array}{l}32.480 \\
36.133 \\
39.120 \\
41.701 \\
43.974\end{array}$ \\
\hline $\begin{array}{r}700 \\
800 \\
900 \\
1,000 \\
1,100\end{array}$ & $\begin{array}{l}13.441 \\
13.895 \\
14.247 \\
14.523 \\
14.741\end{array}$ & $\begin{array}{r}9.637 \\
10.142 \\
10.580 \\
10.961 \\
11.295\end{array}$ & $\begin{array}{l}36.364 \\
37.685 \\
38.905 \\
40.040 \\
41.101\end{array}$ & $\begin{array}{l}46.001 \\
47.827 \\
49.485 \\
51.001 \\
52.395\end{array}$ \\
\hline $\begin{array}{l}1,200 \\
1,300 \\
1,400 \\
1,500\end{array}$ & $\begin{array}{l}14.917 \\
15.059 \\
15.176 \\
15.273\end{array}$ & $\begin{array}{l}11.590 \\
11.851 \\
12.085 \\
12.294\end{array}$ & $\begin{array}{l}42.096 \\
43.034 \\
43.921 \\
44.762\end{array}$ & $\begin{array}{l}53.686 \\
54.886 \\
56.006 \\
57.056\end{array}$ \\
\hline
\end{tabular}

TABLE 5. Calculated thermodynamic functions in dimensionless units for $\mathrm{Cl}_{2} \mathrm{C}: \mathrm{CCl}_{2}$ as an ideal gas ${ }^{\mathrm{a}}$

\begin{tabular}{|c|c|c|c|c|}
\hline$T$ & $C_{p}^{\circ} / R$ & $\left(H^{\circ}-E_{0}^{\circ}\right) / R T$ & $-\left(F^{\circ}-E_{0}^{\circ}\right) / R T$ & $S^{\circ} / R$ \\
\hline $\begin{array}{l}{ }^{\circ} K \\
300\end{array}$ & 11.519 & & & \\
\hline $\begin{array}{l}500 \\
b 394.18\end{array}$ & $\begin{array}{l}12.619 \\
12.623\end{array}$ & $\begin{array}{l}\begin{array}{l}8.054 \\
9.021\end{array}\end{array}$ & $\begin{array}{l}33.292 \\
35.622\end{array}$ & $\begin{array}{l}\text { 41. } 346 \\
44,643\end{array}$ \\
\hline & 12.679 & 9.074 & 35.755 & 44. 829 \\
\hline 500 & 13. 479 & 9.880 & 37.869 & 47.750 \\
\hline 600 & 14.043 & 10.530 & 39.730 & 50.260 \\
\hline 700 & 14. 449 & 11.062 & 41.395 & 52.457 \\
\hline 800 & 14.747 & 11.505 & 42.902 & 54. 407 \\
\hline 900 & 14.971 & 11.878 & 44. 279 & 56.157 \\
\hline 1,000 & 15.142 & 12.196 & 45.547 & 57. 744 \\
\hline 1,100 & 15. 275 & 12.471 & 46.723 & 59. 193 \\
\hline 1,200 & 15.380 & 12. 709 & 47.818 & 60.527 \\
\hline 1,300 & 15.464 & 12.918 & 48.844 & 61.762 \\
\hline 1,400 & 15. 533 & 13.102 & 49.808 & 62. 910 \\
\hline 1,500 & 15.590 & 13. 266 & 50.718 & 63. 984 \\
\hline
\end{tabular}

s The entries in this table have been corrected for the change of $\mu_{10}$ from 170 to $176 \mathrm{~cm}^{-1}$

b The boiling point of TCE at 1 atmosphere is given by Dreisbach and Shrader as $121.02^{\circ} \mathrm{C}$ [37]. The ice point, as well as the other basic constants needed for the computation of these tables, are taken from [38].
The authors are indebted to Prof. K. S. Pitzer for communicating to them the infrared spectrum of TCE below $190 \mathrm{~cm}^{-1}$, and also acknowledge several helpful discussions with Dr. Takehiko Shimanouchi.

\section{References}

[1] Earle K. Plyler and Nicolo Acquista, J. Opt. Soc. Am. 43, 212 (1953).

[2] G. T. Furukawa, R. E. McCoskey, and M. L. Reilly, J. Research NBS 51, 69 (1953) RP2423.

[3] E. K. Plyler, R. Stair, and C. J. Humphreys, J. Research NBS 38, 211 (1947) RP1769.

[4] D. E. Mann, N. Acquista, and Earle K. Plyler, J. Chem. Phys. 21, 1949 (1953).

[5] J. R. Nielsen, H. H. Claassen, and D. C. Smith, J. Chem. Phys. 18, 812 (1950).

[6] E. K. Plyler, J. Chem. Phys. 16, 1008 (1948).

[7] H. J. Bernstein, J. Chem. Phys, 18, 478 (1950).

[8] P. Torkington and H. W. Thompson, Trans. Faraday Soc. 41, 236 (1945).

[9] A. Monfils and J. Duchesne, J. Chem. Phys. 18, 1415 (1950).

[10] A. Monfils and J. Duchesne, Compt. rend. 236, 685 (1953).

[11] R. L. Arnett and B. L. Crawford, Jr., J. Chem. Phys. 18, 118 (1950).

[12] P. Torkington, Trans. Faraday Soc. 45, 445 (1949).

[13] I. L. Karle and J. Karle, J. Chem. Phys. 18, 963 (1950).

[14] W. W. Coblentz, Investigations of infrared spectra (Publ. Carnegie Inst. of Wash., D. C. No. 35, Part I (1905)).

[15] G. B. Bonino, Gazz. chim. ital. 55, 335 (1925).

[16] B. J. Spence and M. A. Easley, Phys. Rev. 34, 730 (1929).

[17] R. Freymann, Compt. rend. 194, 1471 (1932).

[18] T-Y. Wu, Phys. Rev. 46, 465 (1934).

119] J. Duchesne and M. Parodi, Nature 144, 382 (1939).

[20] P. Pringsheim and B. Rosen, Z. Physik, 50, 741 (1928).

[21] A. Dadieu and K. W. F. Kohlrausch, Sitz. ber. Akad. Wiss. Wien, Math.-naturw. Kl. [II] 138, 635 (1929).

[22] A. Dadieu and K. W. F. Kohlrausch, Monatsh. Chem. 55, $58(1930)$.

[23] V. N. Thatte and S. M. Shahane, Indian J. Phys. 6, 155 (1931).

[24] C. S. Morris, Phys. Rev. 38, 141 (1931).

[25] L. Simons, Soc. Sci. Fennica, Commentationes Phys.Math. 6, No. 13 (1932).

[26] F. Heidenreich, Z. Physik 97, 277 (1935).

[27] T-Y. Wu, J. Chinese Chem. Soc. 4, 402 (1936).

[28] M. Kowalewska, Acta Phys. Polon. 7, 279 (1938).

[29] H. Wittek, Z. physik. Chem. B 48, 1 (1940).

[30] D. H. Rank, N. Sheppard, and G. J. Szasz, J. Chem. Phys. 16, 698 (1948).

[31] S. B. Sanyal, Indian J. Phys. 24, 151 (1950).

[32] K. W. F. Kohlrausch, Ramanspektren (Becker and Esler, Leipzig, 1943).

[33] T-Y. Wu, Vibrational spectra and structure of polyatomic molecules (J. W. Edwards, Ann Arbor, Mich., 1946).

[34] G. Herzberg, Infrared and Raman spectra of polyatomic molecules (D. van Nostrand Co., Inc., New York, N. Y., 1945).

[35] Y. Morino, K. Kuchitsu, and T. Shimanouchi, J. Chem. Phys. 20, 726 (1952)

[36] I. L. Karle and J. Karle, J. Chem Phys. 20, 63 (1952).

[37] R. R. Dreisbach and S. A. Shrader, Ind. Eng. Chem. 41, 2879 (1949).

[38] F. D. Rossini, F. T. Gucker, Jr., H. L. Johnston, Linus Pauling, and G. W. Vinal, J. Äm. Chem. Soc. 74, 2699 (1952).

Washington, October 2, 1953. 